\title{
Leadership approaches in law enforcement: A sergeant's methods of achieving compliance with racial profiling policy from the front line
}

\author{
Paul B. Rinkoff*
}

\begin{abstract}
This research aims to fill a void in the extant policy implementation literature that has overlooked the leadership contribution of sergeants to the successful adoption of policy decisions by front-line police officers. Using a qualitative approach and a sociological institutionalism perspective, and focusing on the racial profiling policy of a large North American municipal police organization, 17 sergeants representing 17 divisions (precincts) were interviewed. This research does not aim to assess the efficacy of the selected policy but, rather, examines leadership and supervisory perspectives relating to implementation and compliance. The findings demonstrate the methods used by sergeants to influence and achieve the compliance of front-line police officers with the racial profiling policy. Methods include auditing, being present, training, encouraging, rewarding, and disciplining. To explain these methods, it is theorized that sergeants blend two leadership approaches to ensure front-line officers conform to the racial profiling policy: an authoritative leadership approach and a supportive leadership approach. This study emphasizes the leadership contributions of sergeants when attempting to implement perceived controversial or unpopular policy—in this case, racial profiling policy-in a police organization and contains implications for law enforcement leaders, oversight committees, policy writers, and all government legislators who oversee public safety and security.
\end{abstract}

Key Words Supervision; policy; police; policy implementation.

\section{INTRODUCTION}

Since the seminal writings of Lipsky (1980), which focused on the administrative discretion of "street-level bureaucrats," researchers have sought to explain the failure of front-line workers to commit and respond to explicit policy decisions provided by and implemented from the "top" (Brunetto \& Farr-Wharton, 2005; Ford, 1999; Howlett \& Ramesh, 2003; May \& Winter, 2009; Riccucci et al., 2005; Young, 2000). For government officials and public sector leaders, this issue remains critical because the commitment and responses of "street-level implementers" continues to be thought of as necessary when attempting to achieve desirable policy outcomes (Ewalt \& Jennings, 2004).

Comparatively, police organizations have been charged with "implementation failures" inherent to the unpredictable and conflicting commitment and responses of front-line officers to policy decisions-especially those that are perceived controversial (Skogan, 2008). Resonant in policing scholarship is the finding that general resistance to policy implementation is common and fierce (Buerger, 2002; Phillips, 2015; Skogan, 2008; Stanko, 2007; Warren \& TomaskovicDevey, 2009). One explanation for this phenomenon relies on the influence of external and internal factors that exist in a police organization that can facilitate or hinder frontline officers conforming to policy decisions (Rinkoff, 2018). Internal factors stem from a police organization's unique authoritative structure and composition: one that is hierarchical, professionalized, centralized, and differentiated from others by common frames of reference, common language, and assumptions-forming a unique culture and contributing to a unique sociological perspective among police officers (Schein, 1993). This monolithic conceptualization of "police culture" (see Banton, 1964; Cain, 1973; Rubinstein, 1973; Skolnick, 1966; Westley, 1970) has long been acknowledged as a significant contributor to the

Correspondence to: Paul B. Rinkoff, PhD, Policy Studies, Ryerson University, Policy Studies, Ryerson University, Toronto, ON M5B 2K3, Canada.

E-mail: prinkoff@ryerson.ca

To cite: Rinkoff, B. (2021). Leadership approaches in law enforcement: A sergeant's methods of achieving compliance with racial profiling policy from the front line. Journal of Community Safety and Well-Being, 6(1), 38-45. https://doi.org/10.35502/jcswb. 177

(C) Author(s) 2021. Open Access. This work is distributed under the Creative Commons BY-NC-ND license. For commercial re-use, please contact sales@sgpublishing.ca.

g.PUBLISHING Published by SG Publishing Inc. CSKA Official publication of the Community Safety Knowledge Alliance. 
informal norms and values that shape the everyday decisions and practices of police officers (Loftus, 2010). On the other hand, there is a growing argument that the depiction of a singular, universal culture that unites police officers and ascribes "normal" attitudes and outlooks may be overstated (Paoline, 2003; Paoline et al., 2000). Instead, changes in the composition of police organizations and philosophies over the past three decades, such as professionalization, bringing increasing standards of education, more racialized and female officers, more officers from different social and cultural backgrounds, and other developments in policing services (a shift to community policing models and a customer-service orientation) (Loftus, 2010) have led a number of scholars to argue that police culture should be conceptualized in the plural. The advantage of the rearmost view acknowledges the variable and contextual quality of relations that exist between the police and the public, which has the potential to impact the compliance choices of police officers and, in doing so, influence the methods used by sergeants to control such activities at the street level (Brown \& Benedict, 2002; O'Connor, 2008; Tyler, 2005).

Not only is it important to understand how the environmental and structural factors of police organizations impact choices of front-line officers to conform to policy, but it is equally important that we continue to grow our understanding of the level of influence, if any, that frontline supervisors have on these choices. This study further explores this latter area of inquiry, seeking answers in the unique occupational environment of police officers, in an attempt to confirm, as supported by the literature, that frontline supervisors-in a law enforcement context-are capable of influencing front-line compliance with policy decisions.

\section{The Role of Sergeants in Police Organizations}

The literature shows strong support for the ability of frontline supervisors, namely sergeants, to leverage occupational culture, in particular aspects of rank and structure, to achieve policy goals. This is primarily due to the inherently top-down managerial style of police organizations-one that remains militaristic and bureaucratic (Chan, 1997). Sergeants act as a facilitating layer of management and are relied upon to influence the administration of new and existing policy at the street level (Engel 2001; Skogan, 2008). This influence has been deemed critical for achieving the successful implementation of, and compliance with, new or reformed policy (Britz \& Payne, 1994; Charles et al., 1992; Ingram \& Weidner, 2011; Phillips, 2015; Skogan, 2008; Skogan \& Hartnett, 1997). Based on these findings, it is unsurprising that Engel and Worden (2003, p. 133) have proclaimed sergeants "the most proximate and perhaps most potent bureaucratic force" in police organizations, when it comes to policy implementation and compliance at the front line.

\section{How Do Sergeants Lead?}

Front-line police work is unique and creates challenges for sergeants especially when assessing and achieving conformity (Ingram \& Weidner, 2011). Johnson (2015) suggests that three issues complicate the supervision of front-line officers. First, the complexity, work task ambiguity, and subjectivity of police officer responses to citizen needs make it problematic for sergeants to provide consistent and effective feedback.
Second, police officers are constantly juggling conflicting goals and performing duties of a contradictory nature, rendering it difficult for sergeants to supply specific guidance to officers on how best to execute their responsibilities. Third, due to the larger number of police officers relative to sergeants and the general low visibility of officer assignments, it is not possible to acquire consistent firsthand knowledge of how officers are performing.

Additional leadership challenges for sergeants stem from front-line officers' ability to exercise a high degree of discretion both in their choice of self-initiated activities during "unassigned time" (Famega et al., 2005) and in their judgements related to how, when, and to whom they apply internal policy or legislation (selective enforcement) (Wortley, 2003). Chan (1996) also emphasizes the sizable amount of discretion that characterizes front-line policing and suggests that these working conditions, combined with low visibility and minimal supervision, are a recipe for police practices that tend to bypass or defy legal procedures and formal policies. Compounding this phenomenon is the anomalous relationship that exists between front-line officers and their supervisors-one often defined by uncertainty, suspicion, cynicism, and distrust stemming from the potential for scrutiny and punitive outcomes when the officers are found to be failing to conform to departmental policy or the law (Johnson, 2015; Paoline, 2003). These challenges underscore how important it is for sergeants to adopt a leadership approach that effectively ensures front-line officers conform to unpopular policy decisions.

Engel and Worden (2003) help inform our understanding of the leadership approaches and methods used by sergeants at the front line to achieve policy objectives. In their work, they introduce two leadership models: the "command model" and the "exchange or bargaining model." In the command model, supervisory influence relies on formal authority to achieve compliance with rules and procedures. Alternatively, in the exchange or bargaining model, the capacity to achieve compliance is proportionate to the rewards offered to subordinates. These two models allow us to further explore the complexities of conformity and leadership in a police organization and assist us when unpacking the broader environment or "institution" in which a sergeant operates. These types of application and analysis are essential since the operational environment of a sergeant is not static, nor does a sergeant lead or influence, make decisions, or provide direction to front-line officers from within a vacuum.

\section{The Significance of Examining Racial Profiling Policy}

Racial profiling has been characterized as the most recent expression of hostility that defines the historical and problematic relationship between the police and racialized communities (Glover, 2007; Russell, 2001; Smith, 2007; Weitzer \& Tuch, 2002, 2004). Its association with abusive policing practices (Gross \& Livingston, 2002; Ramirez et al., 2000; Tanovich, 2006) has led to the popular term "Driving while Black" (Harris, 1997, p. 546) and an emphasis on "Black crime," "Black criminality" (Tator \& Henry, 2006, p. 20), and "Blackness as an indicator of criminal tendencies" (Carter Jr., 2004, p. 20).

Amid tenacious advocacy from politicians, legal and civil rights groups, academics, journalists, and activists, 
many police organizations across North America have implemented policies designed to prohibit racial profiling. These implementations are critical given that "racial profiling policies" have been reported to promote more racially equitable policing and improve relations between police officers and racialized communities (Miller, 2013).

In the case of the racial profiling policy (the policy) under review, its measures were designed to regulate voluntary police-citizen interactions (those outside of detention or arrest) to ensure that they are conducted without bias or discrimination (Ministry of Community Safety \& Correctional Services, 2016a). For instance, the policy's measures require police officers to inform citizens of the reasons for any voluntary interaction and their legal rights, provide "receipts" to citizens after any such interaction, and participate in enhanced diversity training (Ministry of Community Safety \& Correctional Services, 2016b).

Despite this policy's best intentions, many rank-and-file officers have suggested that its "unpopular" implementation comes at a great cost to public safety, instilling perceived controversy regarding its practice among officers (Gillis, 2015). This observation is consistent with other implementations of racial profiling policies by police organizations in North America (Fridell et al., 2001; Klinger, 2004). It is the perceived controversy of this policy held by some front-line officers that hinders the policy environment and provides us an opportunity to further inform our understanding of how sergeants-acting as a facilitating layer of management (Skogan, 2008)-direct, control, and secure compliance (Iannone et al., 2009) in ways that may be critical for achieving planned outcomes.

\section{METHODS}

A qualitative research methodology was used, allowing a variety of opportunities for real-life experiences to inform policy-making and policy decisions (Graham \& McDermott, 2006). In addition, the current study relied on a sociological institutionalism perspective-often employed in research involving specialized "organizational fields" in the public sector-aiming to produce a "detailed history of the institutionalization of specific ideas or norms in organizational settings" and "thick descriptions of subtle and dynamic processes, which are not usually easily apprehended by their subjects" (Lowndes \& Roberts, 2013, p. 33).

To further our understanding of the leadership contributions of sergeants, we examined the key methods used by sergeants to influence and achieve conformity of front-line police officers to the policy. Seventeen sergeants from a large North American municipal police service (greater than 5,000 sworn officers), each representing a different division (precinct), were interviewed. Interviews ranged in length from approximately 45 minutes to two hours. The number of sergeants interviewed in this research is supported in the literature. On the higher side, Creswell (2013) suggests that a well-saturated theory can be achieved after 20 to 30 interviews amid several visits to the field. On the lower side, Guest et al. (2006) suggest thematic saturation may be reached in as few as 12 interviews when the data is rich, in-depth, homogeneous, and accurate. These sample sizes are further supported by consensus theory, which postulates that small samples are sufficient to provide suitable information within a specific cultural context if participants possess some expertise related to the area of inquiry (Romney et al., 1986).

A survey questionnaire was also administered to the participants to supplement the data collected from the interviews. Additional data collected included demographic data, work experience, leadership style, communication style, policy knowledge, and other self-reported beliefs, attitudes, and behaviours. The use of this questionnaire is supported by Neuman and Robson (2012), who suggest that measurement and analysis of additional variables allow for additional testing of hypotheses, the inference of any temporal order, and the confirmation or denial of data collected during interviews with participants.

The interviews in this study were semi-structured and conducted face-to-face with participants. Advantages of face-to-face interviews include "high response rates and the longest questionnaires" (Neuman \& Robson, 2012, p. 176) as well as richer and more detailed qualitative data (Berg \& Lune, 2012). The data-recording procedures and the interview and observational protocols included note-taking, audio-recording, full transcription, and coding using QSR International's NVivo 11.4.3 Software (NVivo Qualitative Data Analysis Software, 2017). The coding process facilitated the conceptual abstraction of data and its reintegration as theory (Holton, 2010). Thematic analysis permitted the extraction of concepts from the raw data, which were developed in terms of their properties and dimensions into key themes for inclusion in the findings (Braun and Clarke, 2006; Corbin \& Strauss, 2008).

\section{Selection of Participants}

The literature distinguishes patrol sergeants, termed "street sergeants," from administrative sergeants, termed "station house sergeants" (Van Maanen, 1983). Patrol sergeants spend their time in the field directly monitoring officers. Administrative sergeants are more likely to remain inside a police building and engage in administrative tasks that do not include direct and regular monitoring of officers in the field. In order to ensure that all participants had experienced the process under investigation and were able to contribute to theory construction, this research sampled patrol sergeants only-a data collection method referred to as theoretical sampling (Corbin \& Strauss, 2008) or purposive sampling (Miles et al., 2014). The divisional cross-representation of sergeants ensured that the interviewers got a sense of the varying factors, if any, that may influence a sergeant's capacity to achieve compliance, and any differing degrees of resistance or conformity to the policy under examination from front-line officers.

\section{RESULTS}

\section{Sergeant Demographics}

Of the 17 participants interviewed, $88.2 \%$ were male and $11.8 \%$ were female. In terms of their age, the majority of the study participants were 35 to $44(47.1 \%)$ years of age and 45 to 54 years of age $(41.2 \%)$, which is to be expected, given that promotion to the rank of sergeant generally occurs after officers have been on the job for a decade or more. Participants 
also reported relatively high education levels, with $35.3 \%$ reporting completing some university and $54.3 \%$ reporting holding a university degree or college diploma. This is also expected, given that completed post-secondary education is considered an important attribute of officers who wish to apply for promotion to the rank of sergeant.

The self-reported ethnicity of the participants was South Asian and Caucasian. Some participants preferred not to answer the questions about ethnicity and age, which may have led to underreporting the true number of racialized sergeants who participated in this study. Therefore, it is possible that the sample of sergeants was more ethnically diverse than what was reported. The majority of participants had between 16 and 20 years (52.9\%) of policing experience and 1 to 5 years $(64.7 \%)$ of supervisory experience. Only four participants $(23.5 \%)$ had 11 or more years of supervisory experience. Lower levels of supervisory experience are expected as many officers over the past few years have been newly promoted to sergeant, likely replacing the retiring baby boomer generation.

\section{Analysis of the Methods used by Sergeants to Achieve Conformity}

The thematic analysis relied on both the "prevalence" and "keyness" of a theme for inclusion in the findings (Braun \& Clarke, 2006). It is also important to acknowledge that thematic saturation (Holton, 2010) was detected as early as the thirteenth qualitative interview. Data from the interview and supplemental questionnaire showed empirical support for the methods used by sergeants to achieve compliance of front-line officers with the policy. These methods were: (1) auditing; (2) being present; (3) training; (4) encouraging; (5) rewarding; and (6) disciplining.

\section{Auditing}

Participants reported that reviewing interactions captured on audio or video files, radio transmissions, and related records is one way to discover non-conforming behaviours. Consequently, auditing activities motivate officers to conform to the policy. This finding is consistent with the literature, which suggests that sergeants may positively influence the compliance behaviours of police officers by regularly reviewing their activities (Buerger, 2002; Ingram \& Weidner, 2011; Schafer \& Martinelli, 2008; Stanko, 2007). As one participant stated:

Anytime an officer puts over [broadcasts on the police radio] I'm stopping to investigate one [person]. There are procedures in place: that they activate the camera, activate their microphone, and do everything they can to make sure the investigation takes place in front of the, uh, recording system. I'll make mental note of that stop, I will go back in a day or two to review. If I couldn't attend myself, I will review the video, see how they did, see how their approach was, see what they got out of it, was it within the legislation?

\section{Being Present}

Participants indicated that they are also likely to discover nonconforming behaviours of officers when at hand, intervening when necessary, and offering guidance. Participants asserted that the presence of sergeants at radio calls motivates their officers to conform to the policy. This finding accords with the previous scholarship, which reports that "active" supervisors, who spend more time in the field overseeing their officers, will have a positive (conforming) impact on the behaviour of their officers (Engel, 2000). One respondent disclosed:

I have to make sure as a supervisor that they're not stopping anybody, uh, for no reason. Um, that they're not profiling, uh, so, and by doing that, it's about being out there and watching to see what they do.

\section{Training}

Participants conveyed that if officers are properly trained to understand the requirements of the policy and how to apply it on the road, they are more likely to conform to it. The participants advised that they increase their officers' familiarity with the policy by personally reviewing it with them and by developing in-house training initiatives. This finding is also supported by the scholarship, which suggests that proper training can have a positive impact on the activities of police officers (Bradstreet, 1997). As one respondent explained:

We did a bunch of scenarios, "what-if" situations, and we talked about it as they became more familiar with it. It was almost like a light bulb went off and some of them, like okay this really isn't a big deal, we're still doing what we normally do, you just have to articulate, you know what I mean, articulate why you're doing it a little bit more and they realized it wasn't a huge deal.

\section{Encouraging}

Participants explained that if they spoke with front-line officers in motivational ways and provided examples of the benefits of conforming to the policy, they observed that their officers were more driven to follow the rules. Participants described how they would offer their officers "protection" from unjustified allegations from either the public or management in exchange for conforming behaviours. This finding aligns with the literature, which demonstrates that "supportive sergeants" make their officers feel more reassured when executing their duties and less likely to face discipline if they make a mistake (Engel, 2001). As one respondent illustrates:

I was honest, I said, "this [the policy] is not gonna make our job any easier, that's the truth. I will be lying to you and I would lose credibility if I was to say it's going to make the job easier or better...I understand that, but the reason why we have to learn it, and the reason why you have to understand it, and the reason why you have to still value it as a tool, is...a circumstance may arise, where you consciously, and your police instincts are gonna put you in a position where you're gonna have to get somebody's, ask somebody their name right and if you're in that position you need to know what to do." 


\section{Rewarding}

Participants admitted that they will reward police officers either formally (for instance, a letter in their personnel file) or informally (for instance, via peer recognition, preferred assignment, or approved time off) when they demonstrate conforming behaviours. Participants reported that the act of rewarding encourages similar behaviours in other officers. This finding aligns with the scholarship, which suggests that rewards given by sergeants to officers are an effective means to get them to follow directives (Engel \& Worden, 2003). In the words of one respondent:

I could speak to the detective, the detective sergeant, "hey that was great work by officer A, that's great work." Maybe that detective sergeant that hasn't even spoken to that officer, actually goes up and says, "you know I really appreciate it"...that means a lot to a worker, a handshake, more than a lousy 4 hours or 8 hours [paid reward]. Sometimes a "thanks, that's a good job" you know, to a real police officer that's a big deal.

\section{Disciplining}

Participants conveyed that one of their roles is to hold officers accountable and discipline officers when they do not conform to policy in formal ways (including documentation in their personnel file, reduction in their pay, demotion, or loss of their job) or in informal ways (such as warnings, embarrassment in front of their peers, undesirable assignments, or refusal of time off). This finding is consistent with the literature, which suggests that in many bureaucratic organizations, administrators punish employees in cases when they fail to comply with orders (Redlinger, 1994). As one officer noted:

It all comes down to the severity of what they've done... But at the end of the day, that's a risk that has to be identified quickly and stomped on...It all depends on the officer and their history. Is there a history of this? Then maybe it would have to result to putting it to paper. Is this a one-off situation, where maybe I'm speaking to and explaining, going over procedure, going over, this is what you did, let's watch the video, what were you thinking here? You know, something like that. But if you have a person that had a history of non-compliance of different types of things, you have to deal with it more seriously because it's only going to grow.

The above findings demonstrate support for the analytical model presented below in Figure 1, illustrating the methods used by sergeants to achieve compliance of front-line officers with the policy.

\section{DISCUSSION}

The "command model" and the "exchange or bargaining model" of leadership developed by Engel and Worden (2003) complement the above findings, and have the ability to further our understanding of them. With appropriate integration, it is theorized that sergeants select methods that are used to achieve the compliance of front-line officers with the policy by blending the payoffs of two leadership approaches: authoritative and supportive leadership.

\section{The Authoritative Leadership Approach}

The effectiveness of an authoritative leadership approach is supported by the work of Engel and Worden (2003), who, in proposing a "command model of supervisory influence," theorize that the actions and decisions of front-line officers are restricted through the application of a sergeant's formal authority. In this study, the methods used by sergeants that align with an authoritative leadership approach include: "auditing," "being present," and "disciplining." For instance, the findings suggest that auditing by sergeants regulates the amount of discretion front-line officers enjoy when interacting with members of the public. This is particularly important because the literature suggests that officers' abilities to exercise a high degree of discretion in their choice of selfinitiated activities (for instance, which members of the public officers choose to investigate) is problematic for achieving conformity (Chan, 1996; Famega et al., 2005; Van Maanen, 1983). The problem of front-line officer discretion is further magnified when officers are able to exercise considerable judgment related to how, when, and to whom they apply rules and regulations (Wortley, 2003). As one participant stated:

We have a compliance check that we do every single day... watching a video, depending on what its title, like criminal...provincial offences, we will watch those...everything is being recorded...to ensure that they're [police officers] being professional.

Nevertheless, it is important to point out that an authoritative leadership approach may deemphasize the importance of seeking community feedback and approval, deprioritize community relations, and discourage new initiatives that depart form aggressive law enforcement tactics (Engel, 2001). These purported trends, combined with the inadequacies of the top-down command structure abstracted from the literature, suggest that an authoritative leadership approach, when used by sergeants exclusively, may not prevent front-line officers from failing to conform to the policy. Therefore, it may be beneficial for sergeants to supplement their methods with a supportive leadership approach for the reasons discussed below.

\section{The Supportive Leadership Approach}

A supportive leadership approach agrees with Engel and Worden's (2003) "exchange or bargaining model of supervisory influence," which postulates that the actions and decisions of front-line officers are proportionate to the support and rewards offered. Rewards might consist of protection from internal discipline, but may also include small favours, as was noted in this study's findings. In addition, a supportive leadership approach may be more conducive to the contextual and subjective front-line environments that officers encounter (Johnson, 2015), enabling sergeants to modify the type of support they provide to the specific needs of their officers. In this study, it is proposed that the methods used by sergeants that align with a supportive leadership approach include: "rewarding," "training," and "encouraging." For instance, rewarding may be considered 
a supportive leadership approach because it motivates frontline officers to conform to the policy in the absence of direct supervision. According to one participant:

A lot of benefit comes from simply having your supervisor walk by you in and amongst your peers and go, "really good job on that, keep up the good work." It's a 10-second piece of a day that has a ripple effect not only on the officer continuing the work in that ethical, professional, whatever the law, policy, manner, but it has a ripple effect on others that are listening to it.

In this case, rewarding influences front-line officers to make decisions that surpass policy compliance expectations for a grander purpose: to seek recognition from peers, superiors, and the public in situations that do not require the physical presence of a supervisor. This is significant because sergeants cannot be present at all times and supervise all front-line activities (Kappeler et al., 1994). Therefore, a supportive leadership approach is compelling because it encourages officers to conform to policies without explicit orders from sergeants or their direct presence.

However, it is important to recognize that a supportive leadership approach used in isolation may be unsuited to achieve adequate levels of compliance with policy decisions. This is in large part due to the lack of emphasis that this approach places on holding officers accountable for their actions when they do not conform to directives (Engel, 2001). This shortcoming, conveyed in the literature and in the findings of this study, offers a compelling case for sergeants to combine this approach with the authoritative leadership approach discussed above.

In sum, to achieve the compliance of front-line officers with the policy, it is proposed that sergeants adopt the methods identified in this study: (1) auditing, (2) being present, (3) training, (4) encouraging, (5) rewarding, and (6) disciplining and, in doing so, benefit from the payoffs of two leadership approaches: authoritative and supportive. Importantly, these two leadership approaches are not duelling or mutually exclusive and can be combined in effective ways to achieve greater levels of compliance from front-line officers.

Figure 1 illustrates the integration of the two leadership approaches, with the six methods used by sergeants to achieve compliance of front-line officers with the policy.

\section{Policy Implications}

The findings support a number of policy implications for law enforcement leaders, oversight committees, policy-writers, and all government legislators who oversee public safety and security. First, it must be recognized that sergeants do not lead policy implementations from within a vacuum. On the contrary, in a police organization, particularly at the front lines, there is a conflux of environmental and cultural factors that may facilitate or hinder a sergeant's capacity to ensure front-line officers conform to policy decisions. These factors are often contextual and may vary across the police organization from one police division to another. For instance, Sparrow et al. (1990) and Cain (1973) refer to the unique social, political, legal, and organizational contexts that differ among officers and that may operate to shape the

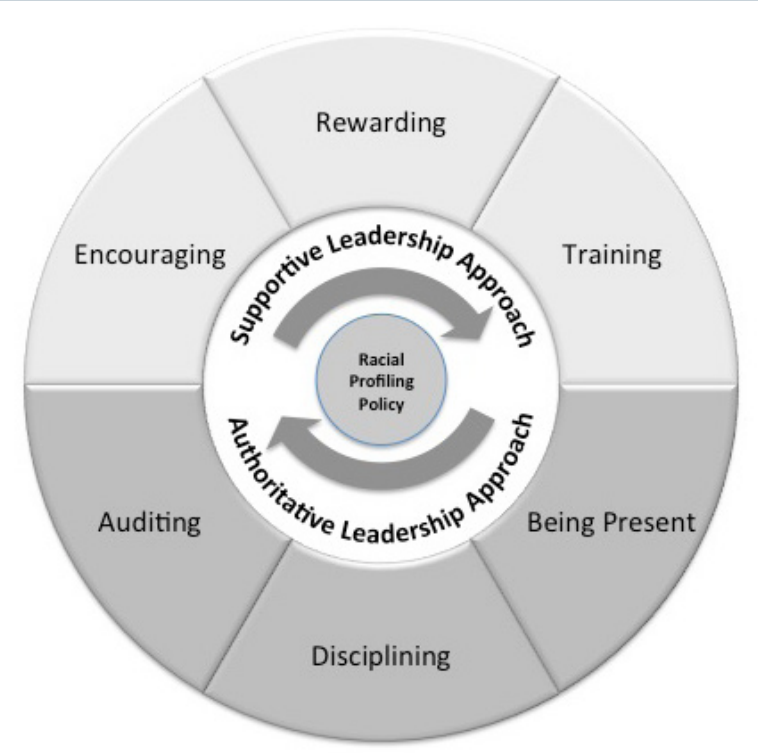

FIGURE 1 Analytical model illustrating the leadership approaches and methods used by sergeants to achieve the compliance of front-line officers with the racial profiling policy

culture. Similarly Reiner (2010, pp. 116-117) suggests that an officer's cultural experience is "neither monolithic, universal, nor unchanging" and embodies the distinctive problems that operate in an officer's environment. Consequently, what might represent the ideal implementation environment for one sergeant may be different from the ideal environment for another. Therefore, the leadership approaches and the methods used by sergeants, particularly when attempting to implement policy that is perceived to be controversial, should take into account the variable nature of the front-line environment, contextualizing directives when necessary to reduce the likelihood of policy failure.

Second, it is important to recognize that sergeants are integral for communicating and translating new policies into action (Skogan, 2008). Moreover, it is clear from the literature that sergeants are "powerful in the change equation" and can contribute to the legitimacy of a new policy or program (Brunetto \& Farr-Wharton, 2005, p. 226). Accordingly, police leaders and executives ought to consult sergeants at the outset of the development of a policy so that new or unpopular implementations are less likely to experience resistance when delivered to the front line.

Third, in relation to racial profiling policies, the findings demonstrate that when sergeants are present during a police-citizen interaction, front-line officers are more likely to conform to policy decisions. Therefore, to improve levels of compliance, racial profiling policies should clearly outline when the presence of a sergeant is necessary. Mandating the presence of a sergeant may ensure an increase in compliance from front-line officers when compliance is expected to be, or has historically been, low or in other perceived controversial policy environments. This is further supported by the research of Bradstreet (1997), who concludes with certainty that it is the sergeant who is best positioned to provide objective assessments of policy outcomes administered at the front line. 


\section{CONCLUSION}

This study demonstrates additional support for the critical leadership contributions of sergeants when attempting to implement perceived controversial or unpopular policy in a police organization. The leadership approaches and methods presented in this study should be examined by sergeants, leaders in law enforcement, and policy-writers so that they may further their understanding of the challenging policy environments which operate at the front lines of police organizations and improve compliance with policy decisions when and where it matters the most.

\section{CONFLICT OF INTEREST DISCLOSURES}

The author acknowledges his dual identity as researcher and policing professional and declares that there are no financial conflicts of interest.

\section{AUTHOR AFFILIATIONS}

* Policy Studies, Ryerson University, Toronto, Ontario, Canada.

\section{REFERENCES}

Banton, M. (1964). The policeman in the community. Tavistock.

Berg, B. L., \& Lune, H. (2012). Qualitative research methods for the social sciences (8th ed.). Pearson.

Bradstreet, R. (1997). Policing: The patrol sergeant's perspective. Journal of Police and Criminal Psychology, 12, 1-6.

Braun, V., \& Clarke, V. (2006). Using thematic analysis in psychology. Qualitative Research in Psychology, 3(2), 77-101. https://doi. org/10.1191/1478088706qp063oa

Britz, M. T., \& Payne, D. M. (1994). Policy implications for law enforcement pursuit driving. American Journal of Police, 13(1), 113.

Brown, B., \& Benedict, W. (2002). Perceptions of the police: Past findings, methodological issues, conceptual issues and policy implications. Violence and Abuse Abstracts, 9(3), 0923.

Brunetto, Y., \& Farr-Wharton, R. (2005). The role of management post-NPM in the implementation of new policies affecting police officers' practices. Policing: An International Journal of Police Strategies \& Management, 28(2), 221-241. https://doi. org/10.1108/13639510510597870

Buerger, M. (2002). Supervisory challenges arising from racial profiling legislation. Police Quarterly, 5131, 380-408. https://doi. org/10.1177/109861102129198200

Cain, M. E. (1973). Society and the policeman's role. Routledge \& Kegan Paul.

Carter Jr., W. M. (2004). A thirteenth amendment framework for combating racial profiling. Harvard Civil Rights-Civil Liberties Law Review, 39(20), 17-93

Chan, J. (1996). Changing police culture. British Journal of Criminology, 36(1), 109-134. https://doi.org/10.1093/oxfordjournals.bjc. $\mathrm{a} 014061$

Chan, J. (1997). Changing police culture: Policing in a multicultural society. Cambridge University Press.

Charles, M., Falcone, D., \& Wells, E. (1992). Police pursuit in pursuit of policy: The pursuit issue, legal, and literature review. https://www. aaafoundation.org/sites/default/files/PolicePursuit.pdf

Corbin, J. M., \& Strauss, A. L. (2008). Basics of qualitative research: Techniques and procedures for developing grounded theory (Vol. 3e). Sage.

Creswell, J. W. (2013). Qualitative inquiry and research design: Choosing among five approaches (3rd ed.). Merrill.
Engel, R. S. (2000). The effects of supervisory styles on patrol officer behavior. Police Quarterly, 3(3), 262-293. https://doi. org/10.1177/1098611100003003003

Engel, R. S. (2001). Supervisory styles of patrol sergeants and lieutenants. Journal of Criminal Justice, 29(4), 341-355. https:// doi.org/10.1016/S0047-2352/01/00091-5

Engel, R. S., \&Worden, R. E. (2003). Police officers' attitudes, behavior, and supervisory influences: An analysis of problem solving. Criminology, $41(1)$, 131-166. https://doi.org/10.1111/j.1745-9125.2003. tb00984.x

Ewalt, J. A. G., \& Jennings, E. T. (2004). Administration, governance, and policy tools in welfare policy implementation. Public Administration Review, 64(4), 449-462. https://doi:10.1111/ j.1540-6210.2004.00391.x

Famega, C. N., Frank, J., \& Mazerolle, L. (2005). Managing police patrol time: The role of supervisor directives. Justice Quarterly, 22(4), 540-559. https://doi.org/10.1080/07418820500364692

Ford, J. D. (1999). Organizational change as shifting conversations. Journal of Organizational Change Management, 12(6), 480-500. https:// doi.org/10.1108/09534819910300855

Fridell, L., Lunney, R., Diamond, D., \& Kubu, B. (2001). Racially biased policing: A principled response. http://fairandimpartialpolicing.com/ docs/rbp-principled.pdf

Gillis, W. (2015, November 7). Police push back on Ontario's proposed carding regulations. The Toronto Star. http://www.thestar.com/ news/gta/2015/11/07/police-push-back-on-ontarios-proposedcarding-regulations.html

Glover, K. (2007). Police discourse on racial profiling. Journal of Contemporary Criminal Justice, 23(3), 239-247. https://doi. org/10.1177/1043986207306866

Graham, H., \& McDermott, E. (2006). Qualitative research and the evidence base of policy: Insights from studies of teenage mothers in the UK. Journal of Social Policy, 35(1), 21-37. https://doi. org/10.1017/S0047279405009360

Gross, S. R., \& Livingston, D. (2002). Racial profiling under attack. Columbia Law Review, 102(5), 1413-1438. https://doi.org/10.2307/1123676

Guest, G., Bunce, A., \&Johnson, L. (2006). How many interviews are enough? An experiment with data saturation and variability. Field Methods, 18(1), 59-82. https://doi.org/10.1177/1525822X05279903

Harris, D. A. (1997). "Driving while Black" and all other traffic offenses: The supreme court and pretextual traffic stops. The Journal of Criminal Law and Criminology (1973-), 87(2), 544-582. https://doi. org/10.2307/1143954

Holton, J. A. (2010). The coding process and its challenges. Grounded Theory Review: An International Journal, 9(1).

Howlett, M., \& Ramesh, M. (2003). Studying public policy. Oxford University Press.

lannone, N. F., Marvin, D. I., \& Bernstein, J. (2009). Supervision of police personnel (7th ed.). Pearson Prentice Hall.

Ingram, J. R., \& Weidner, R. R. (2011). Front-line supervisors' perceptions of less-lethal force policies: Examining the "transmission belts" of police departments. Journal of Crime and Justice, 34(3), 221-233. https:// doi.org/10.1080/0735648X.2011.609730

Johnson, R. R. (2015). Police organizational commitment. Crime \& Delinquency, 61(9), 1155-1180. https://doi.org/10.1177/0011128712466887

Kappeler, V. E., Sluder, R. D., \& Alpert, G. P. (1994). Forces of deviance: Understanding the dark side of policing. Waveland Press.

Klinger, D. (2004). Environment and organization: Reviving a perspective on the police. Peace Research Abstracts, 41(6), 236062.

Lipsky, M. (1980). Street-level bureaucracy: Dilemmas of the individual in public services. Russell Sage Foundation. 
Loftus, B. (2010). Police occupational culture: Classic themes, altered times. Policing \& Society, 20(1), 1-20. https://doi. org/10.1080/10439460903281547

Lowndes, V., \& Roberts, M. (2013). Why institutions matter: The new institutionalism in political science. Palgrave Macmillan.

May, P. J., \& Winter, S. C. (2009). Politicians, managers, and street-level bureaucrats: Influences on policy implementation. Journal of Public Administration Research and Theory, 19(3), 453-476. https://doi. org/10.1093/jopart/mum030

Miles, M. B., Huberman, A. M., \& Saldana, J. (2014). Qualitative data analysis: A methods sourcebook (3rd ed.). Sage.

Miller, K. (2013). The institutionalization of racial profiling policy: An examination of antiprofiling policy adoption among large law enforcement agencies. Crime \& Delinquency, 59(1), 32-58. https:// doi.org/10.1177/0011128708328863

Ministry of Community Safety \& Correctional Services. (2016a). Ontario prohibits carding and street checks, sets out new rules for police interactions. https://news.ontario.ca/mcscs/en/2016/3/ontarioprohibits-carding-and-street-checks-sets-out-new-rules-for-policeinteractions.html?_ga=1.208154450.1344306441.1464111631

Ministry of Community Safety \& Correctional Services. (2016b). 0 . Reg. 58/16: Collection of identifying information in certain circumstances - prohibition and duties. https://www.ontario.ca/ laws/regulation/r16058?_ga=1.220498520.1344306441.14 64111631

Neuman, W. L., \& Robson, K. (2012). Basics of social research: Qualitative and quantitative approaches (2nd ed.). Pearson Allyn and Bacon.

NVivo Qualitative Data Analysis Software. (2017). QSR International Pty Ltd. Version 11.4.3.

O'Connor, C. D. (2008). Citizen attitudes toward the police in Canada. Policing: An International Journal of Police Strategies \& Management, 37(4), 578-595. https://doi.org/10.1108/13639510810910571

Paoline, E. A. (2003). Taking stock: Toward a richer understanding of police culture. Journal of Criminal Justice, 31(3), 199-214. https:// doi.org/10.1016/S0047-2352/03/00002-3

Paoline, E. A., Myers, S. M., \& Worden, R. E. (2000). Police culture, individualism, and community policing: Evidence from two police departments. Justice Quarterly, 17/31, 575-605. https://doi. org/10.1080/07418820000094671

Phillips, S. W. (2015). The attitudes and goals of police supervisors: Results from a national sample. Police Practice and Research, 16(5), 364-377. https://doi.org/10.1080/15614263.2014.888349

Ramirez, D., McDevitt, J., \& Farrell, A. (2000). A resource guide on racial profiling data collection systems: Promising practices and lessons learned. Northeastern University with Support by the U.S. Department of Justice. https://www.ncirs.gov/pdffilesl/ $\mathrm{bja} / 184768 . \mathrm{pdf}$

Redlinger, L. (1994). Community policing and changes in the organizational structure. Journal of Contemporary Criminal Justice, 10(1), 36-58. https://doi.org/10.1177/104398629401000104

Reiner, R. (2010). The politics of the police (4th ed.). Oxford University Press.

Riccucci, N., Meyers, M., \& Lurie, I. (2005). The implementation of welfare reform policy: The role of public managers in front-line practices. Human Resources Abstracts, 40(1), 0262

Rinkoff, P. B. (2018). Street checks and carding: An exploration of a sergeant's capacity to achieve policy conformance from frontline police officers (unpublished PhD thesis). Ryerson University, Toronto, Canada.

Romney, A. K., Weller, S. C., \& Batchelder, W. H. (1986). Culture as consensus: A theory of culture and informant accuracy. American Anthropologist, 88(2), 313-338.

Rubinstein, J. (1973). City police. Farrar, Straus \& Giroux.

Russell, K. K. (2001). Racial profiling: A status report of the legal, legislative, and empirical literature. Rutgers Race and The Law Review, 3(61), $61-81$.

Schafer, J. A., \& Martinelli, T. J. (2008). First-line supervisor's perceptions of police integrity. Policing: An International Journal of Police Strategies \& Management, 37121, 306-323. https://doi. org/10.1108/13639510810878749

Schein, E. H. (1993). On dialogue, culture, and organizational learning. Organizational Dynamics, 22(2), 40-51. https://doi. $\mathrm{org} / 10.1016 / 0090-2616 / 93 / 90052-3$

Skogan, W. G. (2008). Why reforms fail. Policing and Society, 18(1), 23-34. https://doi.org/10.1080/10439460701718534

Skogan, W. G., \& Hartnett, S. M. (1997). Community policing, Chicago style. Oxford University Press.

Skolnick, J. (1966). Justice without trial: Law enforcement in democratic society. Wiley.

Smith, C. C. (2007). Conflict, crisis, and accountability: Racial profiling and law enforcement in Canada. Canadian Centre for Policy Alternatives.

Sparrow, M. K., Moore, M. H., \& Kennedy, D. M. (1990). Beyond 911: A new era for policing. Basic Books.

Stanko, B. (2007). From academia to policy making. Theoretical Criminology, 11(2), 209-219. https://doi.org/10.1177/1362480607075848

Tanovich, D. M. (2006). The colour of justice: Policing race in Canada. Irwin Law.

Tator, C., \& Henry, F. (2006). Racial profiling in Canada: Challenging the myth of "a few bad apples." University of Toronto Press.

Tyler, T. R. (2005). Policing in black and white: Ethnic group differences in trust and confidence in the police. Police Quarterly, 8(3), 322-342. https://doi.org/10.1177/1098611104271105

Van Maanen, J. (1983). The boss: First-line supervision in an American police agency. In M. Punch (Ed.), Control in police organization (pp. 275-317). MIT Press.

Warren, P. Y., \& Tomaskovic Devey, D. (2009). Racial profiling and searches: Did the politics of racial profiling change police behavior? Criminology \& Public Policy, 8(2), 343-369. https:// doi.org/10.1111/i.1745-9133.2009.00556.x

Weitzer, R. (2002). Incidents of police misconduct and public opinion. Journal of Criminal Justice, 30151, 397-408. https://doi. org/10.1016/s0047-2352(02)00150-2

Weitzer, R., \& Tuch, S. (2004). Race and perceptions of police misconduct. Social Problems, 51(3), 305-325.

Westley, W. (1970). Violence and the police: A sociological study of law, custom and morality. MIT Press.

Wortley, R. (2003). Measuring police attitudes toward discretion. Criminal Justice and Behavior, 3015), 538-558. https://doi. org/10.1177/0093854803254805

Young, A. P. (2000). "I'm Just Me". Journal of Organizational Change Management, 13(4), 375-388. https://doi. org/10.1108/09534810010339068 